\section{COMMENTS AND RESPONSES}

\section{Surgery Versus Nonsurgical Treatment of Lumbar Spinal Stenosis}

TO THE EDITOR: I found Delitto and colleagues' article (1) at odds with not only my experience but that of other published studies. The way that the data and results were reported leaves more questions than answers.

The authors do not state whether the 169 patients who were deemed eligible for surgery had physical therapy (PT) first. If not, the 87 patients assigned to surgery had no PT, which, in an elective setting, is a breach of the standard of care. If so, then we can assume that PT was unsuccessful in all 169 patients.

Of the 82 patients assigned to PT, only 29 finished the treatment, with 15 improving. The authors state that improvement in 15 of 29 patients equals a $52 \%$ success rate. A more accurate description of this group's outcome is that 15 of the 82 original patients improved, which equals an $18 \%$ success rate. The authors address this discrepancy by stating that the high percentage of crossovers or patients leaving the PT group for the surgery group "presents a challenge in interpretation." Indeed. Knowing why so many patients left the PT group would have been useful.

Although the authors do not cite the number of patients who completed PT, most patients in the PT group seem not to have completed the proscribed therapy, leading the authors to declare, "We did not see a relationship between attendance in PT and outcome, including the probability of success." That is, PT had no bearing on outcome in this group.

The success rate in the surgery group was $61 \%$. The text states that 33 surgical complications occurred; the accompanying table lists 22 . The text states that 11 complications occurred in patients who crossed over from PT to surgery, of which there were 44 . These 11 complications are not detailed. The complication rates for surgery in this study were high; they occurred in 22 of 74 patients (30\%) who had surgery in the original surgery group and in 11 of 44 patients (25\%) in the crossover surgery group. The combined surgical complication rate was 33 of 118 patients (28\%). This rate is higher than that reported in other surgical series and may explain the overall surgical success rate of $61 \%$, which is lower than that in many other reported studies. The Discussion section does not address this possibility.

For these reasons, among others not included here, the authors' conclusions are highly suspect.

Steven J. Barrer, MD

Abington Memorial Hospital

Abington, Pennsylvania

Disclosures: Authors have disclosed no conflicts of interest. Forms can be viewed at www.acponline.org/authors/icmje/ConflictOf InterestForms.do?msNum=L15-0315.

\section{Reference}

1. Delitto A, Piva SR, Moore CG, Fritz JM, Wisniewski SR, Josbeno DA, et al. Surgery versus nonsurgical treatment of lumbar spinal stenosis: a randomized trial. Ann Intern Med. 2015;162:465-73. [PMID: 25844995] doi:10.7326/M14 $-1420$
TO THE EDITOR: We congratulate Delitto and colleagues (1) for conducting a randomized, controlled trial comparing surgery with PT for the treatment of lumbar spinal stenosis (LSS). However, we have serious concerns about their methods, particularly their interpretation of the results. We do not agree that the study shows that "surgical decompression yielded similar effects to a PT regimen among patients with LSS who were surgical candidates." We believe that adherence to intention-to-treat analysis severely distorts the results and leads to erroneous conclusions.

Figure 1 indicates that almost two thirds of suitable patients (312 of 481) declined to participate and to be randomly assigned. No information on these patients was presented, but, on the basis of previous, larger, similar studies, these nonparticipants probably experienced greater disability than those who volunteered for randomization $(2,3)$. This factor raises doubts about this study's external validity.

Of the patients allocated to PT, $57 \%$ crossed over to surgery after receiving an average of 7.8 PT sessions. In the "real world," crossover equates to treatment failure, yet the authors do not seem to acknowledge this when analyzing PT success. As treated, only 15 of 73 PT patients (21\%) had a "successful" outcome. Two patients crossed over from surgery to PT, presumably doing so before surgery took place. This circumstance delineates the near impossibility of performing a randomized, controlled trial between surgical and nonsurgical care options and represents temporal inequality.

The value of intention-to-treat analysis in maintaining the benefits of randomization is clear when crossover rates are low and study groups compare equivalent medical treatments. However, this method is inappropriate when comparing surgical versus nonsurgical treatments when crossover is high in 1 study group. Such trials tend to select a cohort of mildly severe cases of the study condition and have prolonged delays in recruitment, as did this one.

In clinical practice, many patients have had unsuccessful experiences with nonsurgical care, including PT, before considering surgery for a degenerative disorder, such as LSS. As Delitto and colleagues' study shows, some will experience satisfactory improvement with PT. However, this study also shows that many persons with substantial disability will opt out of PT and instead choose surgical decompression. Including these patients as PT "successes" is therefore inappropriate. To suggest that this study's findings show equivalence of PT and surgery represents a failure of the study's methods and analysis. Comparing surgical versus nonsurgical therapies with high crossover remains a challenge for methods of evidencebased medicine.

Peter A. Robertson, MD

Auckland Hospital

Auckland, New Zealand

William R. Sears, MBBS

Wentworth Spine Clinic Sydney, Australia

John E. Cunningham, BSc, MBBS, MClinEpi

Royal Melbourne Hospital

Melbourne, Australia

396 × 2015 American College of Physicians 
Disclosures: Disclosures can be viewed at www.acponline.org /authors/icmje/ConflictOflnterestForms.do?msNum=L15-0316.

\section{References}

1. Delitto A, Piva SR, Moore CG, Fritz JM, Wisniewski SR, Josbeno DA, et al. Surgery versus nonsurgical treatment of lumbar spinal stenosis: a randomized trial. Ann Intern Med. 2015;162:465-73. [PMID: 25844995] doi:10.7326/M14 $-1420$

2. Weinstein JN, Tosteson TD, Lurie JD, Tosteson A, Blood E, Herkowitz H, et al. Surgical versus nonoperative treatment for lumbar spinal stenosis four-year results of the Spine Patient Outcomes Research Trial. Spine (Phila Pa 1976). 2010;35:1329-38. [PMID: 20453723] doi:10.1097/BRS .0b013e3181e0f04d

3. Weinstein JN, Lurie JD, Tosteson TD, Tosteson AN, Blood EA, Abdu WA, et al. Surgical versus nonoperative treatment for lumbar disc herniation: fouryear results for the Spine Patient Outcomes Research Trial (SPORT). Spine (Phila Pa 1976). 2008;33:2789-800. [PMID: 19018250] doi:10.1097/BRS .0b013e31818ed8f4

TO THE EDITOR: Delitto and colleagues (1) conclude that surgical decompression yielded effects similar to those of a PT regimen among LSS surgical candidates. The authors recommend decision-making conversations between patients and health care providers, as has been previously stated (2).

Data to guide providers and patients in complex judgments about LSS were not specified and have not been conclusive $(2,3)$. Treatment of this condition was described as a balancing act needing an expansive research agenda (2). Randomized trials show average efficacy of therapy and do not reveal different clinical subgroups within a broad spectrum of disease (4). Individual distinctions are crucial features of good patient care and concerns for what patients feel, think, or want (4).

Delitto and colleagues state, "The surgical approach in these studies has been highly standardized." However, opinions differ on whether to perform decompression with or without fusion or instrumentation (5). Of note, a person's medical and physical circumstances and expected quality-of-life outcomes further complicate treatment decisions in LSS. A chronic disease model may preferably be applied to this condition. Elements can include effective communication among professionals, including PT, primary or specialist medical providers, and consulting surgeons; patient-focused education and services; and coordination of cost-effective, timely, and evidence-based interventional managements or procedures. The complexity of LSS merits research on personalized management and outcome studies.

In a private context, one of us was diagnosed with multilevel, bilateral, severe (as shown on magnetic resonance imaging), symptomatic LSS in December 2013, and decision making was difficult. The patient-clinician was knowledgeable in spine biomechanics and clinical epidemiology, and decompressive surgery took place on 10 March 2015. Previous chronic stiffness of the lower extremities, tightness, and guarded gait were promptly relieved, and he resumed his academic office functions 3 weeks after surgery. Home PT is increasing lower-extremity strength and coordination. Even if this favorable personal assessment persists and could be completely objective, as Aristotle stated, "One swallow does not a summer make."

We call for research in personalized assessment and management of patients in the multifaceted LSS spectrum, includ- ing validated rating scales for the severity of central stenosis and objective evaluations of patients' physical functioning, neurologic status (such as deficits), overall physical condition, and expected quality of life. Such systematic data gathering and tracking of the course of this chronic and progressive disorder could help attain more timely personalized decisions shared by informed patients and designated providers.

Alfonse T. Masi, MD, DrPH

Sam Betts, PT, DPT, MOMT

University of Illinois College of Medicine at Peoria and Midwest Orthopaedic Center

Peoria, Illinois

Disclosures: Authors have disclosed no conflicts of interest. Forms can be viewed at www.acponline.org/authors/icmje/ConflictOf InterestForms.do?msNum=L15-0317.

\section{References}

1. Delitto A, Piva SR, Moore CG, Fritz JM, Wisniewski SR, Josbeno DA, et al. Surgery versus nonsurgical treatment of lumbar spinal stenosis: a randomized trial. Ann Intern Med. 2015;162:465-73. [PMID: 25844995] doi:10.7326/M14 $-1420$

2. Deyo RA. Treatment of lumbar spinal stenosis: a balancing act. Spine J. 2010;10:625-7. [PMID: 20620984] doi:10.1016/j.spinee.2010.05.006

3. Weinstein JN, Tosteson TD, Lurie JD, Tosteson AN, Blood E, Hanscom B, et al; SPORT Investigators. Surgical versus nonsurgical therapy for lumbar spinal stenosis. N Engl J Med. 2008;358:794-810. [PMID: 18287602] doi:10 .1056/NEJMoa0707136

4. Feinstein AR. Twentieth century paradigms that threaten both scientific and humane medicine in the twenty-first century. J Clin Epidemiol. 1996;49:615-7 [PMID: 8656219]

5. Irwin ZN, Hilibrand A, Gustavel M, McLain R, Shaffer W, Myers M, et al. Variation in surgical decision making for degenerative spinal disorders. Part I: lumbar spine. Spine (Phila Pa 1976). 2005;30:2208-13. [PMID: 16205348]

IN RESPONSE: We agree with Dr. Barrer that conservative care should precede considering surgery. However, we disagree that not having prior PT is a "breach of . . . care." Exactly what constitutes conservative care is not universally agreed upon. Physical therapy is 1 form, as is watchful waiting, epidural steroids, drug regimens, and many combinations. In our study, surgeons deemed patients surgical candidates largely because conservative care-including, in some cases, previous PT-had been unsuccessful.

As for the high crossover rate, complier average causal effect and inverse probability weighting analyses were done to address that issue. In terms of success rates of surgery, it would be helpful if Dr. Barrer had included references, because definitions of success can vary. We defined it as improvement by an SD of 0.5 regardless of crossover status, because we believed that the risks of surgery warranted setting a high bar.

As for the implication that the surgical group did not fare well overall, the plot of the group means suggests otherwise and strongly parallels the outcomes of the surgical groups in SPORT (Spine Patient Outcomes Research Trial) and Malmivaara and colleagues' trials. The text and Appendix Table 4 of our article list 33 complications (22 in the surgery group and 11 in the PT group) that the table clearly details. Other studies that actually surveyed complications had similar 
rates (for example, the reoperation rate was $8 \%$ in SPORT and $6 \%$ in Malmivaara and colleagues' trial) $(1,2)$.

In response to Dr. Robertson and associates, we agree that generalizability of study results was limited to patients who agreed to a $50 \%$ chance to be randomly assigned to PT. Most patients who declined random assignment cited the strong desire to have surgery as the reason, and it cannot be assumed that these results would generalize to that group. Understanding that internal versus external validity is a balancing act, we sacrificed generalizability to strengthen internal validity by reducing crossover in at least 1 of the study groups.

We disagree that the number of PT sessions is related to treatment failure. The most often-cited reason for discontinuing PT was the burden of copayments. As for the 2 crossovers from surgery to PT, we agree that it is impossible to perfectly compare surgical versus nonsurgical care. However, with such a minuscule crossover rate in the surgical group, we believe that we achieved the goal of reducing crossover in 1 group, allowing for meaningful intention-to-treat analyses. We agree that crossovers in the PT group presented a challenge in analyses, something that we tried to address using complier average causal effect and inverse probability weighting.

Anthony Delitto, PT, PhD

Sara R. Piva, PT, PhD

Charity G. Moore, PhD, MSPH

William C. Welch, MD

University of Pittsburgh

Pittsburgh, Pennsylvania

Disclosures: Disclosures can be viewed at www.acponline.org /authors/icmje/ConflictOfInterestForms.do?msNum=M14-1420.

\section{References}

1. Weinstein JN, Tosteson TD, Lurie JD, Tosteson AN, Blood E, Hanscom B, et al; SPORT Investigators. Surgical versus nonsurgical therapy for lumbar spinal stenosis. N Engl J Med. 2008;358:794-810. [PMID: 18287602] doi:10 .1056/NEJMoa0707136

2. Malmivaara A, Slätis $P$, Heliövaara M, Sainio $P$, Kinnunen $H$, Kankare J, et al; Finnish Lumbar Spinal Research Group. Surgical or nonoperative treatment for lumbar spinal stenosis? A randomized controlled trial. Spine (Phila Pa 1976). 2007;32:1-8. [PMID: 17202885]

\section{Efficacy of Commercial Weight-Loss Programs}

TO THE EDITOR: Gudzune and colleagues (1) do not acknowledge the lack of evidence showing that dieting-induced weight loss reduces mortality or cardiovascular events in obese persons. In a large, multicenter intensive diet and lifestyle intervention trial, cardiovascular events (heart disease, stroke, and cardiovascular-related deaths) did not decrease in obese and overweight diabetics despite these participants losing $6 \%$ of their body weight with a median follow-up of 9.6 years (2). Although the large, sustained weight loss associated with bariatric surgery decreases mortality in morbidly obese patients (3), weight loss from dieting has not shown similar benefits (4). In contrast, improving cardiorespiratory fitness in obese persons reduces the risk for all-cause and cardiovascular disease mortality (5). Given the unproven benefits and difficulty of maintaining diet-induced weight loss, clinicians are best advised to focus on improving cardiorespiratory fitness and metabolic risk factors in their obese patients. The evidence base justifying the medical management of obesity with improved fitness and exercise is stronger than that for weight loss from dieting and referrals to commercial weightloss programs.

James T. Langland, MD

University of Minnesota

Minneapolis, Minnesota

Disclosures: Authors have disclosed no conflicts of interest. Forms can be viewed at www.acponline.org/authors/icmje/ConflictOf InterestForms.do?msNum=L15-0313.

\section{References}

1. Gudzune KA, Doshi RS, Mehta AK, Chaudhry ZW, Jacobs DK, Vakil RM, et al. Efficacy of commercial weight-loss programs: an updated systematic review. Ann Intern Med. 2015;162:501-12. [PMID: 25844997] doi:10.7326/M14-2238 2. Wing RR, Bolin P, Brancati FL, Bray GA, Clark JM, Coday M, et al; Look AHEAD Research Group. Cardiovascular effects of intensive lifestyle intervention in type 2 diabetes. N Engl J Med. 2013;369:145-54. [PMID: 23796131] doi:10.1056/NEJMoa1212914

3. Sjöström L, Narbro K, Sjöström CD, Karason K, Larsson B, Wedel H, et al; Swedish Obese Subjects Study. Effects of bariatric surgery on mortality in Swedish obese subjects. N Engl J Med. 2007;357:741-52. [PMID: 17715408] 4. Kritchevsky SB, Beavers KM, Miller ME, Shea MK, Houston DK, Kitzman DW, et al. Intentional weight loss and all-cause mortality: a meta-analysis of randomized clinical trials. PLoS One. 2015;10:e0121993. [PMID: 25794148] doi:10 .1371 /journal.pone. 0121993

5. Lee DC, Sui X, Artero EG, Lee IM, Church TS, McAuley PA, et al. Long-term effects of changes in cardiorespiratory fitness and body mass index on allcause and cardiovascular disease mortality in men: the Aerobics Center Longitudinal Study. Circulation. 2011;124:2483-90. [PMID: 22144631] doi:10 .1161/CIRCULATIONAHA.111.038422

TO THE EDITOR: Gudzune and colleagues' review (1) underscores the need to enhance the modest weight loss that lifestyle or behavioral interventions typically produce. However, the manner in which they convey the designs and results of the included trials, although succinct, could be misinterpreted. First, the authors describe the comparators for the commercial programs as "control/education" (that is, placebo) or "behavioral counseling" (that is, active control). "Behavioral counseling" does not completely describe the comparator interventions, many of which included dietary and physical activity counseling over many visits and some of which differed only in terms of the macronutrient composition (2-4). Second, the authors summarize the results as mean differences between the commercial programs and their comparators, emphasizing comparative effectiveness instead of overall effectiveness (that is, changes from baseline). For example, they report the results of the Atkins studies as " $0.1 \%$ to $2.9 \%$ greater weight loss at 12 months than counseling," but the weight loss achieved during the study for the Atkins interventions ranged from $3.4 \%$ to $12.9 \%$. Thus, reporting additional summary data for an intervention, such as mean weight loss from baseline with a $\mathrm{Cl}$, would also be informative. The editorial mentions the possible misinterpretation of results presented in this way by stating that these programs caused "negligible to modest weight loss" (5). A more accurate state- 
ment would be "negligible to modest additional weight loss compared with programs of established effectiveness." Because many participants have achieved substantial weight loss with these commercial programs, we should be cautious about discouraging their use on the basis of their average comparative effectiveness.

William S. Yancy Jr., MD

Anna Beth Barton, MD

Megan A. McVay, PhD

Corrine I. Voils, PhD

Center for Health Services Research in Primary Care, Veterans Affairs Medical Center, and Duke University School of Medicine

Durham, North Carolina

Disclosures: Disclosures can be viewed at www.acponline.org /authors/icmje/ConflictOfInterestForms.do?msNum=L15-0312.

\section{References}

1. Gudzune KA, Doshi RS, Mehta AK, Chaudhry ZW, Jacobs DK, Vakil RM, et al. Efficacy of commercial weight-loss programs: an updated systematic review. Ann Intern Med. 2015;162:501-12. [PMID: 25844997] doi:10.7326/M14-2238 2. Foster GD, Wyatt HR, Hill JO, Makris AP, Rosenbaum DL, Brill C, et al. Weight and metabolic outcomes after 2 years on a low-carbohydrate versus low-fat diet: a randomized trial. Ann Intern Med. 2010;153:147-57. [PMID: 20679559] doi:10.7326/0003-4819-153-3-201008030-00005

3. Gardner CD, Kiazand A, Alhassan S, Kim S, Stafford RS, Balise RR, et al. Comparison of the Atkins, Zone, Ornish, and LEARN diets for change in weight and related risk factors among overweight premenopausal women: the A TO Z Weight Loss Study: a randomized trial. JAMA. 2007;297:969-77. [PMID: 17341711]

4. Shai I, Schwarzfuchs D, Henkin Y, Shahar DR, Witkow S, Greenberg I, et al; Dietary Intervention Randomized Controlled Trial (DIRECT) Group. Weight loss with a low-carbohydrate, Mediterranean, or low-fat diet. N Engl J Med. 2008; 359:229-41. [PMID: 18635428] doi:10.1056/NEJMoa0708681

5. Wee CC. The role of commercial weight-loss programs [Editorial]. Ann Intern Med. 2015;162:522-3. [PMID: 25845000] doi:10.7326/M15-0429

IN RESPONSE: Dr. Langland states that modest weight loss achieved through lifestyle change has failed to reduce mortality or cardiovascular events and that referrals to commercial weight-loss programs should therefore be avoided. Although we agree that long-term benefit for cardiovascular events or mortality through modest weight loss has not been proved, clinical guidelines from the American Heart Association, American College of Cardiology, The Obesity Society (1), and the U.S. Preventive Services Task Force (2) currently recommend weight loss for its benefits regarding diabetes, hypertension, and cholesterol levels. In fact, the U.S. Preventive Services Task Force recommends that clinicians "screen all adults for obesity and offer or refer patients with a [body mass index] of $30 \mathrm{~kg} / \mathrm{m}^{2}$ or higher to intensive, multicomponent behavioral interventions." Because most clinicians do not offer multicomponent interventions in their offices, our review is designed to help them discuss commercial weight-loss options with their patients.

Dr. Yancy and colleagues note that the term "behavioral counseling" might not completely describe the comparator interventions that included counseling on diet, exercise, or behavior modification of varying intensities. We acknowledge the heterogeneity of counseling comparators, which contributed to our decision not to present meta-analyses. We provided details about all comparator and intervention groups in Table 4 of the Supplement. Dr. Yancy and colleagues also expressed concern about the presentation of only comparative effectiveness results. Our stated purpose was to compare weight loss from commercial weight-loss programs versus that from control/education or counseling among overweight and obese adults. Thus, we emphasized comparative results to aid clinicians who often must weigh different treatment options for their patients. In fact, obesity counseling in clinical settings could become even more relevant, because it may be increasingly available to patients given recent benefit expansions within Medicare and through the Patient Protection and Affordable Care Act $(3,4)$.

Kimberly A. Gudzune, MD, MPH

The Johns Hopkins University School of Medicine Baltimore, Maryland

Sara N. Bleich, PhD

Johns Hopkins Bloomberg School of Public Health Baltimore, Maryland

Jeanne M. Clark, MD, MPH

The Johns Hopkins University School of Medicine Baltimore, Maryland

Disclosures: Authors have disclosed no conflicts of interest. Forms can be viewed at www.acponline.org/authors/icmje/ConflictOf InterestForms.do?msNum=M14-2238.

\section{References}

1. Jensen MD, Ryan DH, Apovian CM, Ard JD, Comuzzie AG, Donato KA, et al; American College of Cardiology/American Heart Association Task Force on Practice Guidelines. 2013 AHA/ACC/TOS guideline for the management of overweight and obesity in adults: a report of the American College of Cardiology/American Heart Association Task Force on Practice Guidelines and The Obesity Society. Circulation. 2014;129:S102-38. [PMID: 24222017] doi:10 .1161/01.cir.0000437739.71477.ee

2. Moyer VA; U.S. Preventive Services Task Force. Screening for and management of obesity in adults: U.S. Preventive Services Task Force recommendation statement. Ann Intern Med. 2012;157:373-8. [PMID: 22733087]

3. Centers for Medicare \& Medicaid Services. Intensive behavioral therapy for obesity. 3 February 2012. Accessed at www.cms.gov/Regulations -and-Guidance/Guidance/Transmittals/downloads/R142NCD.pdf on 1 June 2015.

4. Congressional Budget Office. Updated estimates of the insurance coverage provisions of the Affordable Care Act. 4 March 2014. Accessed at www.cbo .gov/sites/default/files/cbofiles/attachments/45010-breakout-AppendixB.pdf on 1 June 2015.

\section{Routine Iron Supplementation and Screening for Iron Deficiency Anemia in Pregnancy}

TO THE EDITOR: To interpret the results of the trials included in Cantor and colleagues' review (1), we need to know 1 additional fact: Did the women in fact take the iron pills during pregnancy? If that fact is not known, the trials cannot be interpreted. Although I have no firsthand experience, I have been told that taking iron pills during pregnancy is a daunting task. At best, using the intention-to-treat population, we could con- 
clude that the trials as designed and conducted did not show a benefit. It does not mean that none exists.

Another issue arises when this same question is evaluated in observational studies, where the concepts of "exposure" and "outcome" are explored. To my knowledge, the "exposure" actually consists of exposure to the drug prescription, not to the drug. It would be great if the investigators would include documentation of actual dosing in their publications. The intention-to-treat analysis is superb at controlling type I errors but does not intrinsically ensure that we know exactly which treatment the participants received.

Robert C. Kane, MD

U.S. Food and Drug Administration

Silver Spring, Maryland

Disclosures: Authors have disclosed no conflicts of interest. Forms can be viewed at www.acponline.org/authors/icmje/ConflictOf InterestForms.do?msNum=L15-0319.

\section{Reference}

1. Cantor AG, Bougatsos C, Dana T, Blazina I, McDonagh M. Routine iron supplementation and screening for iron deficiency anemia in pregnancy: a systematic review for the U.S. Preventive Services Task Force. Ann Intern Med. 2015;162:566-76. [PMID: 25820661] doi:10.7326/M14-2932

IN RESPONSE: Dr. Kane suggests that we need to further understand adherence to accurately interpret trial results for iron supplementation in pregnant women. We provided data on adherence (or rather nonadherence) in Appendix Table 4. For the supplementation studies, adherence-usually based on pill counts or an equation involving pill counts-was variably reported and ranged from $54 \%$ to $98 \%$. Seven of 10 studies reported adherence. Although 6 studies found no difference in adherence between the groups, the seventh showed significantly greater adherence in the iron supplementation group (97.8\% vs. $83.9 \% ; P=0.036)(1)$. This study states that adherence corresponds to a "range of 19-74 mg/day in women's average intake of elemental iron during the study period," which encompasses the $30 \mathrm{mg} / \mathrm{d}$ (60 to $100 \mathrm{mg} / \mathrm{d}$ in high-risk women) often recommended for supplementation.

To clarify, the studies in our analysis were randomized, controlled trials; no observational studies were included in our results. Therefore, the exposure in the treatment group for the trials was the actual supplements, not the prescription.

We agree with Dr. Kane that it is helpful to understand the intention-to-treat approach to assess the benefit of iron supplementation but also believe that, to fully understand the outcomes of the trials, we also need to distinguish between the efficacy of the intervention and the effectiveness. We reported on the effectiveness of prenatal iron supplementation, not the efficacy. In evaluating the efficacy of an intervention, adherence to the assigned regimen is required as a part of the study concept. However, when effectiveness is being evaluated, real-world adherence-similar to using the intention-totreat analysis-provides the most accurate picture. Although adherence may certainly contribute to the effectiveness of iron supplementation, any issues related to lack of adherence are an assumed limitation of supplementation trials in general.
Amy G. Cantor, MD, MPH Christina Bougatsos, MPH

Marian McDonagh, PharmD

Pacific Northwest Evidence Based Practice Center, Oregon

Health \& Science University

Portland, Oregon

Disclosures: Disclosures can be viewed at www.acponline.org /authors/icmje/ConflictOfInterestForms.do?msNum=M14-2932.

\section{Reference}

1. Meier PR, Nickerson HJ, Olson KA, Berg RL, Meyer JA. Prevention of iron deficiency anemia in adolescent and adult pregnancies. Clin Med Res. 2003; 1:29-36. [PMID: 15931282]

\section{CORRECTIONS}

\section{Correction: Insurance Plan Presentation and Decision Support on HealthCare.gov and State-Based Web Sites Created for the Affordable Care Act}

In a recent letter (1), an author's name was spelled incorrectly. The correct spelling is "Nirenburg," not "Nirenberg".

This has been corrected in the online version.

\section{Reference}

1. Wong C, Nirenburg G, Polsky D, Town R, Baker T. Insurance plan presentation and decision support on HealthCare.gov and state-based Web sites created for the Affordable Care Act. Ann Intern Med. 2015;163:328. doi:10.7326 /L15-5127

\section{Correction: Sedentary Time and Its Association With Risk for Disease Incidence, Mortality, and Hospitalization in Adults}

A recent meta-analysis (1) inadvertently omitted an eligible paper. The authors of the 2 papers in question were the same (Wijndaele was the first author for both). The authors of the meta-analysis believed that the papers had redundant outcomes (i.e., an update of outcomes from the same cohort). However, Wijndaele et al. (2011; Int J Epidemiol [2]) examined all-cause mortality, CVD mortality, and cancer mortality, whereas Wijndaele et al. (2011; PLoS ONE [3]) examined CVD incidence. Also, the wrong Wijndaele citation was included in Figure 1. The paper has been revised, and both papers are included in the meta-analysis. The results do not meaningfully change with the inclusion of the new study; the point estimates remain significant.

These corrections have been made to the online version

\section{References}

1. Biswas A, Oh PI, Faulkner GE, Bajaj RR, Silver MA, Mitchell MS, et al. Sedentary time and its association with risk for disease incidence, mortality, and hos pitalization in adults: a systematic review and meta-analysis. Ann Intern Med 2015;162:123-32. [PMID: 25599350] doi:10.7326/M14-1651

2. Wijndaele K, Brage S, Besson H, Khaw KT, Sharp SJ, Luben R, et al. Television viewing time independently predicts all-cause and cardiovascular mortality: the EPIC Norfolk study. Int J Epidemiol. 2011;40:150-9. [PMID: 20576628] doi:10.1093/ije/dyq105

3. Wijndaele K, Brage S, Besson H, Khaw KT, Sharp SJ, Luben R, et al. Television viewing and incident cardiovascular disease: prospective associations and mediation analysis in the EPIC Norfolk Study. PLoS One. 2011;6:e20058 [PMID: 21647437] doi:10.1371/journal.pone.0020058 